\title{
Genetic Diversity among CIMMYT Maize Inbred Lines Investigated with SSR Markers: II. Subtropical, Tropical Midaltitude, and Highland Maize Inbred Lines and their Relationships with Elite U.S. and European Maize
}

\author{
X. C. Xia, J. C. Reif, A. E. Melchinger, M. Frisch, D. A. Hoisington, D. Beck, K. Pixley, and M. L. Warburton*
}

\begin{abstract}
Characterization of genetic diversity of maize (Zea mays L.) germplasm is of great importance in hybrid maize breeding. The objectives of this study were to (i) investigate genetic diversity in CIMMYT subtropical, tropical midaltitude and highland inbreds with simple sequence repeat (SSR) markers, (ii) identify appropriate testers for the development of new inbred lines, (iii) compare this sample to U.S. and European elite maize lines and CIMMYT tropical lowland inbreds, and (iv) use the marker and pedigree information as a guide to understanding the heterotic relationship among the CIMMYT maize lines (CMLs) and their potential practical use in maize breeding programs worldwide. Inbreds included in the study were assayed with 79 SSR markers. The CIMMYT inbred lines originated from 35 mostly broad-based populations and pools with mixed origins. A total of 566 alleles were scored, (averaging 7.2 and ranging from 2 to 16 alleles per locus). The modified Roger's distance (MRD) between pairs of inbreds averaged 0.78 , with a range of 0.45 to 0.93 . Unweighted paired group method using arithmetic averages (UPGMA) cluster analysis revealed no clear clustering. This reflects a mixed composition of CIMMYT subtropical, tropical midaltitude and highland maize populations and pools, and indicates that large amounts of variation have been incorporated into CIMMYT germplasm. Temperate heterotic groups were separated based on the markers, and nontemperate CIMMYT maize was genetically distinct from temperate lines. Discrete clusters were difficult to identify within and often between megaenvironments. Specific recommendations for nontemperate hybrid maize breeding are made.
\end{abstract}

$T_{1}$ HE DEFINITION OF HETEROTIC GROUPS and heterotic patterns is an empirical task in hybrid maize breeding that has, in temperate maize germplasm, contributed to large increases in yield. Reciprocal recurrent selection programs (RRS) have proven to be effective in the improvement of heterotic groups for a systematic exploitation of heterosis, as they maximize selection gains within a heterotic group and differences between heterotic groups. Clear characterization of genetic diversity of maize inbred lines derived from different origins will maximize the efficiency in hybrid combinations and the development of new inbreds. In temperate maize such

X.C. Xia, Institute of Crop Breeding and Cultivation, Chinese Academy of Agricultural Sciences, Zhongguancun South Street 12,100081, Beijing, China; J.C. Reif, A.E. Melchinger, and M. Frisch, Inst. of Plant Breeding, Seed Science and Population Genetics, Univ. of Hohenheim, 70593 Stuttgart, Germany; D. Beck, K. Pixley, and M.L. Warburton, CIMMYT, Apdo. Postal 6-641, 06600 Mexico D.F., Mexico; D.A. Hoisington, ICRISAT, Patancheru, Hyderabad 502-324, Andhra Pradesh, India. Received 21 Mar. 2005. *Corresponding author (mwarburton@cgiar.org).

Published in Crop Sci. 45:2573-2582 (2005).

Genomics, Molecular Genetics \& Biotechnology

doi:10.2135/cropsci2005.0246

(C) Crop Science Society of America

677 S. Segoe Rd., Madison, WI 53711 USA as U.S. Corn Belt germplasm, a clear heterotic pattern (Reid Stiff Stalk vs. Lancaster) was established early on and inbred lines such as B73 and Mo17 from the two heterotic groups were chosen as testers for the selection of new maize inbreds. The use of representative testers allows the placement of a new inbred into the appropriate heterotic group using only a small number of field crosses.

In the late 1960s and early 1970s, the maize breeding program of CIMMYT focused on the collection and testing of various sources of maize germplasm. In 1974, CIMMYT breeders began to use this germplasm to create open-pollinated varieties (OPV). These OPV were based on intrapopulation improvement via recurrent selection (Wellhausen, 1978). Approximately 100 populations and 30 genetically broad-based pools were formed, many of which did not adhere to known racial complexes (Vasal et al., 1999). CIMMYT breeders create germplasm suitable for a multitude of environments in which maize is grown worldwide and which differ in growing season temperatures, altitude, and other aspects that affect adaptation. For breeding efficiency, CIMMYT identified four major megaenvironments, and four maize research subprograms address the needs of maize farmers in these areas. The four megaenvironments are (i) tropical lowland, (ii) subtropical, (iii) midaltitude, and (iv) highland megaenvironments.

Following successful deployment of hundreds of OPV in the 1970s and early 1980s, the CIMMYT maize program began the development of hybrid maize to meet the needs of hybrid-oriented farms and markets in the developing world (Vasal et al., 1992a; Beck et al., 1997). Following the decision to initiate a hybrid breeding program, several diallel studies were conducted to investigate heterotic groups and patterns for hybrid breeding among tropical, subtropical, and temperate germplasm (Beck et al., 1991; Crossa et al., 1990; Vasal et al., 1992a, 1992b). However, the mixed constitution of many of the pools and populations made the task of assigning them to genetically diverse and complementary heterotic groups difficult. In the 1990s, 10 pairs of subtropical, midaltitude, and highland populations were identified or formed as heterotic partners. These were subsequently used in RRS programs at CIMMYT to enlarge genetic distance between partner groups and maximize the heterosis between inbred lines selected from complementary populations (S.K. Vasal, 2003, personal communication). The

Abbreviations: CML, CIMMYT maize inbred line; masl, meters above sea level; MRD, modified Roger's distance; OPV, open-pollinated varieties; PCoA, principal coordinate analysis; PIC, polymorphic information content; RRS, reciprocal recurrent selection; SSR, simple sequence repeat; UPGMA, unweighted paired group method using arithmetic averages. 
heterotic patterns include: Pop33 $\times$ Pop45, Pop42 $\times$ Pop44, Pop501 $\times$ Pop502, Pop401 $\times$ Pop402, Pop445 $\times$ Pop446, INT-A $\times$ INT-B, LAT-A $\times$ LAT-B, DR-A $\times$ DR-B, Z97EWA $\times$ Z97EWB, and Pop902 $\times$ Pop903. More recently, testers from each population have been used to identify the hybrid performance of inbreds from the partner populations and help assign new inbred lines into an appropriate heterotic group.

CIMMYT has released 134 subtropical, 38 midaltitude, and 26 highland maize inbred lines to date, which have played an important role in hybrid maize production in developing countries (Morris, 2001; Evenson and Gollin, 2003). Most of these CMLs were developed from approximately 60 genetically broad-based populations and pools of subtropical, midaltitude, and highland megaenvironment adaptation. However, because of the time required for inbred development, few of the lines were extracted from the previously mentioned heterotic patterns. Currently, more CIMMYT breeders are deriving lines from these heterotic patterns. Knowledge of genetic diversity among the maize inbred lines developed for each megaenvironment is of importance in maize breeding for the development of new lines and the assignment of maize inbred lines to distinct heterotic groups. A better understanding of the relationships between inbred lines from different megaenvironments may be useful to incorporate exotic germplasm in an existing breeding program. This is particularly important, as the CIMMYT inbred lines are freely distributed to breeding programs around the world, where they are often crossed to locally adapted inbreds. Better information on how the CMLs are related to lines from different sources may provide guidance to breeders worldwide on how to more efficiently use the CIMMYT lines in their breeding programs.

Pedigree information has traditionally been used to infer relationships between lines and populations in many species, including maize (Duvick, 1984; Smith, 1988; Troyer et al., 1988; Smith and Smith, 1989; Smith et al., 1997). However, because of the largely mixed origin of the populations from which the CMLs were drawn, pedigree information alone may not be sufficient to understand the genetic relationships among these lines. Two lines drawn from the same population or pool may actually be more genetically distinct than two lines drawn from different populations or pools (Warburton et al., 2002; Xia et al., 2004). Molecular markers are a powerful complement to help define heterotic groups and to examine the relationships among inbred lines at the DNA level (Smith et al., 1997; Senior et al., 1998). Various molecular marker types have been used to investigate relationships among inbred maize lines from different heterotic groups (Dubreuil et al., 1996; Smith et al., 1997; Lu and Bernardo, 2001; Yuan et al., 2001; Xia et al., 2004). Markers are also used to assign lines to new or currently existing heterotic groups (Dubreuil et al., 1996; Smith et al., 1997; Yuan et al., 2001).

The objectives of this study were to (i) investigate genetic diversity in CIMMYT subtropical, tropical midaltitude, and highland inbreds with SSR markers; (ii) identify appropriate testers for the development of new inbred lines; (iii) compare this sample to U.S. and European elite maize lines and CIMMYT tropical lowland inbreds; and (iv) use the marker and pedigree information as a guide to understanding the heterotic relationships among the CMLs and their potential practical use in maize breeding programs worldwide.

\section{MATERIALS AND METHODS}

\section{Plant Materials}

A total of 73 subtropical, 22 tropical midaltitude, 11 tropical highland, and 10 tropical lowland CMLs were chosen for characterization. Temperate germplasm was represented by 12 U.S., 1 Canadian, and 8 European maize inbred lines (Table 1). Seeds of the CIMMYT maize inbred lines were obtained from the CIMMYT maize program; seeds of the temperate inbred lines were kindly provided by Iowa State University and the University of Hohenheim. One leaf from each of 10 seedling plants were bulked for each line. DNA was isolated employing the CTAB procedure according to the Applied Biotechnology Center's Manual of Laboratory Protocols (http://www.cimmyt. cgiar.org/ABC/Protocols/manualABC.html; verfied 27 July 2005).

\section{Simple Sequence Repeat Analysis}

The 79 SSR markers used in this study were chosen from the MaizeGDB database (http://www.maizegdb.org/ssr.php; verified 27 July 2005) based on repeat unit and bin location to provide a uniform coverage of the entire maize genome. Primers and PCR conditions were described in detail by Warburton et al. (2002). Fluorescently labeled SSR primers were multiplexed in PCR reactions for maximum efficiency. Amplified fragments were separated in an ABI377 automatic DNA sequencer (Applied Biosystems, Inc., Foster City, CA). Fragment sizes were calculated with GeneScan 3.1 (Perkin-Elmer Ltd., Bucks, UK; and Applied Biosystems, Inc., Foster City, CA) using the Local Southern sizing method (Elder and Southern, 1987); and allele identity was assigned using the category function of Genotyper 2.1 (Perkin-Elmer Ltd., Bucks, UK; and Applied Biosystems, Inc., Foster City, CA). Two inbred lines (CML51 and CML292) were included in every gel as internal quality controls. All data have been submitted for storage in the MaizeGDB database (http://www.maizegdb. org/; verified 27 July 2005) and is available in an ACCESS database on request from CIMMYT.

\section{Statistical Analysis}

The MRD was calculated between each pair of inbred lines as:

$$
\operatorname{MRD}=\sqrt{\frac{1}{2 m} \sum_{i=1}^{m} \sum_{j^{\prime}=1}^{a_{i}}\left(p_{i j}-q_{i j}\right)^{2}},
$$

where $p_{i j}$ and $q_{i j}$ are the allele frequencies of the $j$ th allele at the $i$ th marker in the two lines under consideration, $a_{i}$ is the number of alleles at the $i$ th marker, and $m$ refers to the number of markers (Wright, 1978, p. 91; Goodman and Stuber, 1983). Standard errors were calculated using the jackknife estimator (Melchinger et al., 1991; Messmer et al., 1992). The polymorphic information content (PIC) for each locus was determined as described by Smith et al. (1997). Average linkage (UPGMA) clustering and principal coordinate analysis (PCoA; Gower, 1966) were calculated based on the MRD between all pairs of inbred lines. The genetic analyses were performed using the Plabsim software package (v. 2, Frisch et al., 2000), which 
Table 1. Description of the 73 subtropical, 22 tropical midaltitude, 11 tropical highland, and 10 tropical lowland CIMMYT maize lines (CMLs), plus the 12 U.S., 1 Canadian, and 8 European inbreds used in this study. $\dagger$

\begin{tabular}{|c|c|c|}
\hline $\begin{array}{l}\text { Source of the } \\
\text { germplasm }\end{array}$ & Inbred line & Genetic group \\
\hline $\begin{array}{l}\text { Pool 31 } \\
\text { Pool 32 } \\
\text { Pool 33 } \\
\text { Pool 34 } \\
\text { Pop33 } \\
\text { Pop34 } \\
\text { Pop42 } \\
\text { Pop47 } \\
\text { Pop402 } \\
\text { Pop500 } \\
\text { Pop501 } \\
\text { Pop502 }\end{array}$ & $\begin{array}{l}\text { CML075 } \\
\text { CML077, 078, 081, 083, 111, 117, 129, 177, 179, } 183 \\
\text { CML187 } \\
\text { CML189, 191 } \\
\text { CML113, 323 324 } \\
\text { CML085, 087, 089 } \\
\text { CML091, 093, 095, 097, 099, 131 } \\
\text { CML109, 123 127, 135 137, } 317 \\
\text { CML367, 369 } \\
\text { CML311, 312, 315, } 316 \\
\text { CML313, 379, 381 } \\
\text { CML321, 383, 384, } 385\end{array}$ & $\begin{array}{l}\text { Subtropical non-Tuxpeño related inbreds; Ancestry includes materials } \\
\text { from Ecuador, Argentina, India, Mexico, Brazil, Uruguay, China, Pakistan, } \\
\text { Guatemala, Venezuela, Peru, Cuba, and the U.S. Corn Belt }\end{array}$ \\
\hline $\begin{array}{l}\text { Pop43SR } \\
\text { Pop44 } \\
\text { Pop63 }\end{array}$ & $\begin{array}{l}\text { CML373 } \\
\text { CML101, 103, 105, 107, 133, } 375 \\
\text { CML176 }\end{array}$ & $\begin{array}{l}\text { Subtropical Tuxpeño related inbreds, including American Early Dents } \\
\text { and Tuxpeño components of La Posta }\end{array}$ \\
\hline $\begin{array}{l}\text { Pop45 } \\
\text { Pop68 } \\
\text { Pop590 } \\
\text { Recy.W } \\
\text { Recy.Y } \\
\text { S. Africa } \\
\text { Others }\end{array}$ & $\begin{array}{l}\text { CML325, 327 } \\
\text { CML173, 175 } \\
\text { CML333, 334, 338, 370, } 371 \\
\text { CML319, 331, 377 } \\
\text { CML329, 335, 337 } \\
\text { CML181, 193 } \\
\text { CML119, 121, 139 }\end{array}$ & $\begin{array}{l}\text { Subtropical inbreds from Tuxpeño plus miscellaneous origins; Ancestry } \\
\text { includes materials from the U.S. Corn Belt, Cuba, Puerto Rico, Dominican } \\
\text { Republic, and the Tuxpeño race of collections }\end{array}$ \\
\hline $\begin{array}{l}\text { EV8449 } \\
\text { Pool 16 } \\
\text { Pop43C9 } \\
\text { Pop49 } \\
\text { ZM601 } \\
\text { ZM609 } \\
\text { Others }\end{array}$ & $\begin{array}{l}\text { CML211 } \\
\text { CML440 } \\
\text { CML444 } \\
\text { CML445 } \\
\text { CML386 } \\
\text { CML387, 389 } \\
\text { CML202, 203 }\end{array}$ & $\begin{array}{l}\text { Midaltitude Tuxpeño related inbreds; Ancestry includes materials from } \\
\text { Mexico, the Caribbean, Central and South America, Asia, and the U.S. } \\
\text { Corn Belt }\end{array}$ \\
\hline $\begin{array}{l}\text { EV7992 } \\
\text { EV-POP30 } \\
\text { ZM605 } \\
\text { IITA } \\
\text { Recy.W } \\
\text { MSR }\end{array}$ & $\begin{array}{l}\text { CML206, 207, 209, } 391 \\
\text { CML213 } \\
\text { CML441, 443 } \\
\text { CML395 } \\
\text { CML442 } \\
\text { CML201, 205, 215, } 216\end{array}$ & $\begin{array}{l}\text { Midaltitude non-Tuxpeño related inbreds; Ancestry includes materials } \\
\text { from Europe, Asia, Mexico, Guatemala, and the U.S. Corn Belt }\end{array}$ \\
\hline $\begin{array}{l}\text { Pop800 } \\
\text { Recy.W }\end{array}$ & $\begin{array}{l}\text { CML246, } 355 \\
\text { CML349 }\end{array}$ & $\begin{array}{l}\text { Highland dents and semidents; ancestry includes temperate highland early } \\
\text { white semident germplasm }\end{array}$ \\
\hline $\begin{array}{l}\text { Pop85 } \\
\text { Pop86 } \\
\text { Recy.W }\end{array}$ & $\begin{array}{l}\text { CML239, 241, 242, 243, } 354 \\
\text { CML245 } \\
\text { CML351, } 353\end{array}$ & $\begin{array}{l}\text { Highland flints and semiflint inbreds; ancestry includes } 60 \% \text { tropical highland } \\
\text { germplasm, } 20 \% \text { temperate, and } 20 \% \text { tropical } / \text { subtropical germplasm }\end{array}$ \\
\hline $\begin{array}{l}\text { Pop21 } \\
\text { Pop24 } \\
\text { Pop43 }\end{array}$ & $\begin{array}{l}\text { CML001 } \\
\text { CML021, } 287 \\
\text { CML273 }\end{array}$ & Tropical Tuxpeño related dents; ancestry includes Tuxpeño races from Mexico \\
\hline $\begin{array}{l}\text { Pop32 } \\
\text { Pop62 } \\
\text { Antigua } \\
\text { SA3 } \\
\text { SA8 }\end{array}$ & $\begin{array}{l}\text { CML039 } \\
\text { CML151 } \\
\text { CML059 } \\
\text { CML435 } \\
\text { CML366 }\end{array}$ & $\begin{array}{l}\text { Tropical non-Tuxpeño flints; ancestry includes materials from Cuba, South } \\
\text { America, and USA }\end{array}$ \\
\hline USA and Canada & $\begin{array}{l}\text { B73, B90, B91, B97, B99, B100, B105, B114, R228, } \\
\text { R229, R230; W401; Co125 }\end{array}$ & Temperate maize lines \\
\hline Europe & D06, D32, D171, DK105, KW1, KW2, F2, F7 & Temperate maize lines \\
\hline
\end{tabular}

$\dagger \mathbf{E V}=$ experimental variety; $\mathbf{M S R}=$ maize streak resistance; $\mathbf{P o p}=$ population; $\mathbf{R e c y} . \mathbf{Y}=$ recycled population-yellow; $\mathbf{R e c y} . \mathbf{W}=$ recycled populationwhite; SA = acid soil; TSR = tar spot resistance; SR = streak resistance; ZM = Zimbabwe maize, open-pollinated variety from CIMMYT, Harare, Zimbabwe.

is implemented as an extension to the statistical software $\mathrm{R}$ (Ihaka and Gentleman, 1996).

\section{RESULTS AND DISCUSSION}

\section{Genetic Diversity among the Inbred Lines}

Among the CMLs, a total of 566 alleles were scored for the 79 loci analyzed and the average number of alleles per locus was 7.2, with a range of 2 to 16 . This is similar to the level of diversity found in our previous study of lowland tropical CMLs (7.4 alleles per SSR locus; Xia et al., 2004). Lower levels of allelic diversity were found in elite U.S. maize inbreds (Senior et al., 1998; Smith et al., 1997). The PIC values in this study for the 79 SSR loci ranged from 0.16 to 0.88 , with an average of 0.64 . These results were similar to those reported in previous studies of lowland tropical CMLs (Betrán et al., 2003; Xia et al., 2004) and in U.S. maize inbreds (Smith et al., 1997; Senior et al., 1998). The inbreds from the U.S. and Europe amplified a total of 344 alleles, of which 22 were unique and were not found in the CIMMYT lines. Of the 566 alleles that amplified in the CIMMYT lines, 244 were unique to the CIMMYT lines (did not amplify in the U.S. and European materi- 
als). Together, these results indicate a higher number of alleles present in the CIMMYT germplasm in comparison with temperate maize inbred line, but many of these alleles are present at low frequencies. They also suggest that some divergence has occurred between the highly diverse tropical and subtropical lines representing the center of origin of maize, and the newer temperate germplasm, and also that much diversity from the center of origin has not been incorporated into temperate materials. These results are in agreement with those reported by Rebourg et al. (2003), who found an apparent genetic separation between European and Latin American maize germplasm with few exceptions in the characterization of 129 European and 88 American maize populations.

The average MRD between pairs of inbred lines in this study was 0.78 , with a range from 0.45 to 0.93 , which is similar to that found in our previous study of CIMMYT tropical inbred lines (Xia et al., 2004). These values are lower than distances reported in previous studies of temperate maize inbreds (Enoki et al., 2002; $\mathrm{Lu}$ and Bernardo, 2001; and Pejic et al., 1998). The lower average MRD in the current survey suggests a higher average degree of relatedness among the subtropical, midaltitude, and highland CMLs than among temperate adapted inbred lines with well-established heterotic groups. This is consistent with results in the previous study of the CIMMYT lowland tropical inbred lines (Xia et al., 2004) and reflects the mixed constitution of CIMMYT germplasm, and the low variance between populations used for the extraction of inbred lines (Warburton et al., 2002).

Over all SSR markers, $6.4 \%$ of the inbred lines showed heterozygosity or heterogeneity (two alleles) for a given marker on average (data not shown). This is low and what is often found for highly inbred lines (for example, Gethi et al., 2002). The extra allele in these cases would not influence the average genetic distances between inbred lines.

\section{Grouping of Germplasm}

Before 1984, CIMMYT developed broad-based composites and populations, which were useful sources of OPV when further selected within a more specific target environment by national programs and private breeders. Some heterotic patterns have been suggested at the population level and several pairs of heterotic populations have been improved by RRS in different megaenvironments since 1990. To determine placement into heterotic groups and heterotic patterns of inbred lines selected from these populations, testers with good general combining ability and per se performance were employed in the hybrid breeding program. Nevertheless, based on the marker data, it is apparent that the divergence between the heterotic groups in RRS programs at CIMMYT is not nearly as large as that of the temperate adapted germplasm. This is especially true when RRS has not been employed in inbred line improvement at CIMMYT. The smaller divergence is most likely due to the intermixing of the original populations and the relatively recent creation of the heterotic pairs. Heterotic responses in tropical maize can be expected to be lower than responses seen in temperate germplasm when crossing between heterotic groups. In the following sections, we discuss the groupings (and/or separations) seen based on genetic distance in each megaenvironment separately.

\section{Subtropical Megaenvironment}

Subtropical CMLs have been bred for the areas of maize production from 23 to $34^{\circ} \mathrm{N}$ and from 23 to $34^{\circ} \mathrm{S}$, with an altitude $<1600$ masl (meters above sea level). There are approximately 10 million hectares of maize grown in this environment. In the CIMMYT subtropical maize breeding program, 55 populations and pools were formed using germplasm from diverse sources in Latin America, Asia, Europe, and the USA. Twenty-five white and 10 yellow populations have been employed for the development of inbred lines. Of these, three pairs of white populations (Pop42 $\times$ Pop44, Pop401 $\times$ Pop402, and Pop501 $\times$ Pop502) and two pairs of yellow populations (Pop33 $\times$ Pop45 and Pop445 $\times$ Pop446) have been either formed or assigned to opposite heterotic groups and have been improved by RRS since 1990. Five white CMLs (CML078, CML311, CML321, CML373, CML384) are employed as testers in the subtropical breeding program; CML078, CML311, and CML373 represent heterotic group A (CML078 and CML373 are derived from Tuxpeño race germplasm, CML311 from non-Tuxpeño), while CML321 and CML384 are from heterotic group $\mathrm{B}$ and originated from South American and U.S. Corn Belt germplasm. Similarly, CML327 and CML323 are used as the yellow maize testers from heterotic group $\mathrm{A}$ and $\mathrm{B}$, respectively.

In a cluster analysis of CIMMYT lines, the subtropical lines did not clearly cluster according to their origins or grain color, except for sister lines derived from the same individual of a population (Fig. 1). These results were not unexpected based on the largely mixed composition of many of the CIMMYT subtropical maize populations and pools, and similar origins of white and yellow maize germplasm (although some, such as Pop 32, were formed following studies of heterotic grouping based on field crosses). Similar results are reported in previous studies of CIMMYT germplasm (Warburton et al., 2002; Xia et al., 2004).

The results of a PCoA show good separation between the inbreds selected from the populations in heterotic pattern Pop501 and Pop502 (Fig. 2). Pop501 and Pop502 are relatively newly formed populations composed of 32 and $30 \mathrm{~S}_{4}$ or $\mathrm{S}_{5}$ lines, respectively, which originated from eight commercial U.S. maize hybrids, Kansas City $12 \times$ Pool 31, Pool $32 \times$ Cornell 6606, and Mexican dent maize germplasm. Inbred lines were selected to form the two populations based on their differential cross performance with two testers (CML078 and CML097) representing opposing heterotic groups. Although Pop501 and Pop502 were derived from similar germplasm sources, a clear heterotic pattern was shown between the inbreds extracted from the two populations following one cycle 
CML 189

CML337•

CML078ם

CML101॰

CMLI35口

CML1370

CML181 •

CML193•

CML173•

CML177

(MLO99D

CML $333 \bullet$

(ML338•

CML371 •

CMLI39•

CML083

CMLI87^

CML.329

CML334•

CML.3150

CML335•

CML327•

CML373॰

CML 381

CML 317

CML097D

(ML316

CML324

CML087-

C'ML3234

CML085-

CML077ロ

CML369

CML331•

CMLI17

CMLI330

CMLI07०

CML121

CMLI1I

CML0950

(ML075

CML129

CML1310

(ML370•

(MLI)

CMLI79ם

CMLI 830

CML325•

CML089

CMLI090

CMLO81D

CML311

CML312

CML $375^{\circ}$

CML0915

CMLIO)

CML105॰

CML127ㅁ

CML385 •

CML383

CML384 •

CML379 •

CML377

CML313*

CML176॰

CML321

CML113A

CML123믐

CML093

CML3670

(ML191

(ML175•

CML319•

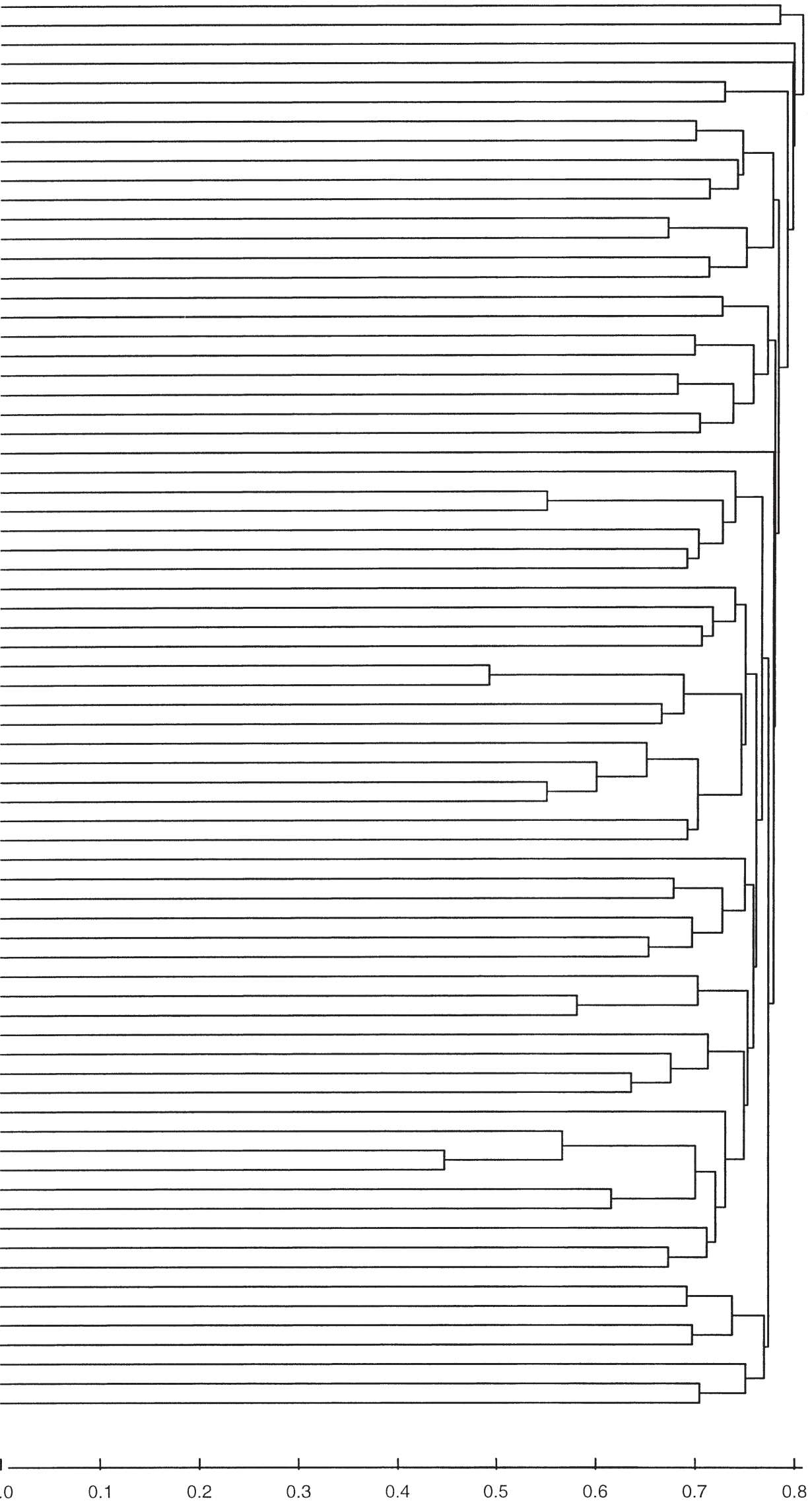

Fig. 1. Associations among subtropical white and yellow inbred lines revealed by unweighted paired group method using arithmetic averages cluster analysis based on modified Roger's distance (horizontal axis). Lines were extracted from Pool31 and Pop34 (ם), Pool32, Pop42, 47,

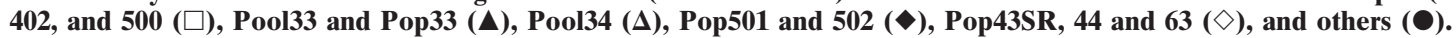




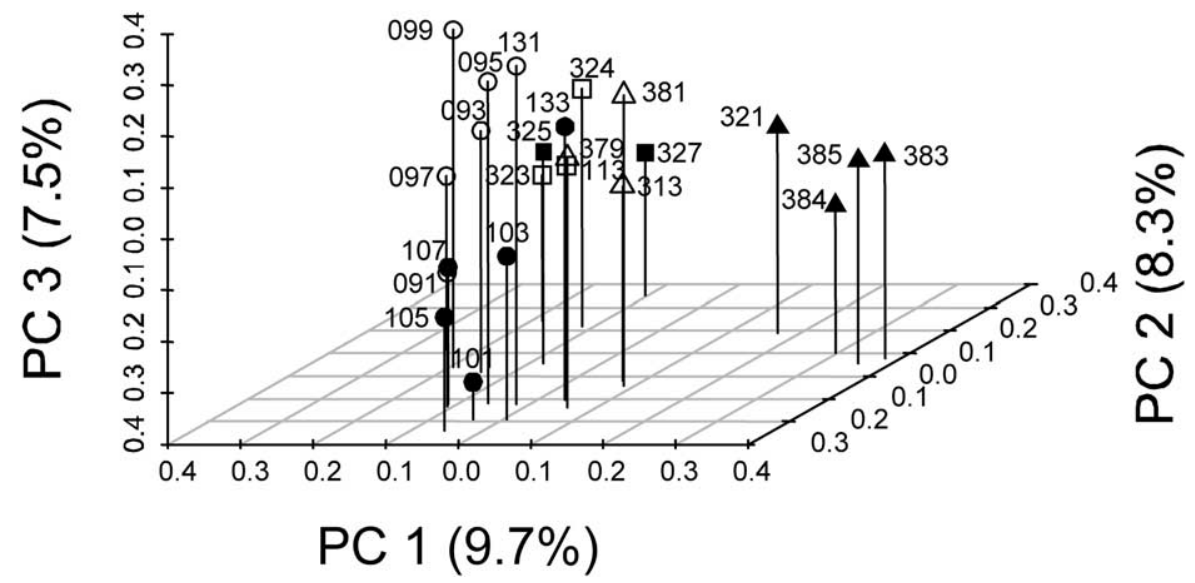

Fig. 2. Principal coordinate analysis based on modified Roger's distance. PC1, PC2, and PC3 are the first, second, and third principal coordinate, respectively. CIMMYT maize lines extracted from three pairs of heterotic populations used in the subtropical hybrid program are Pop33

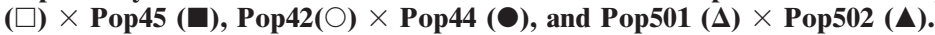

of RRS. They are also clearly separated in the PCoA graph in Fig. 2. Labate et al. (1999) found similar results indicating that genetic distance (as measured by molecular markers) between two heterotic populations can be considerably increased in an RRS program. On the other hand, we found no clear differences between the inbred lines extracted from populations in opposite heterotic patterns such as Pop33 and 45, and Pop42 and 44, populations that also underwent RRS improvement (Fig. 2). These lines are also not clearly differentiated from lines derived from populations that did not undergo RRS. Most of the CMLs tested in our study were derived directly from these populations and we were not able to find discrete heterotic groups among them.

\section{Midaltitude Megaenvironment}

The CIMMYT midaltitude maize breeding program is conducted in Zimbabwe for the seven million hectares of maize grown between the meridians of Cancer and Capricorn at altitudes from 900 to 1500 masl. A total of 15 white maize populations and experimental varieties were employed for the extraction of inbred lines. Of these, 4 pairs of heterotic partner populations (INT-A $\times$ INT-B, LAT-A $\times$ LAT-B, DR-A $\times$ DR-B, and Z97EWA $\times$ Z97EWB) are currently being improved by RRS. The midaltitude inbred lines included in this study were developed from 13 white populations and experimental varieties.

Two semident inbred lines (CML202 and CML206) were used as testers for developing inbred lines during the 1990s. However, both CML202 and CML206 were derived from the germplasm of heterotic group A according to their origins. Thus, selection of inbred lines based on their combining ability should lead to a higher number of lines from heterotic group B. Nevertheless, a converse result was found in that $51 \%$ of midaltitude inbred lines have been assigned to heterotic group A, $29 \%$ to B, and $20 \%$ to both A and B, respectively, based on field crosses (CIMMYT, 2004). This could indicate that CML202 actually belongs to heterotic group B instead of A, which has been suggested as well by some of the breeders using these inbred lines (K. Pixley, 2004, personal communication). Another possibility is that the mixed germplasm forming the source populations of these lines has caused heterotic group A to contain enough variation to display high heterosis in crosses of some inbred lines with both of the testers (and potentially in crosses within the same heterotic group). In agreement with the latter possibility, PCoAs show that the midaltitude CMLs do not group according to their origins; rather, they are evenly distributed (Fig. 3). The choice of testers to represent a heterotic group is of fundamental importance in hybrid breeding. In addition, no single tester can adequately represent very heterogenous heterotic groups. CML202 and CML206 have recently been discontinued as testers because of mixed results in the field (K. Pixley, 2004, personal communication).

\section{Tropical Highland Megaenvironment}

The CIMMYT tropical highland maize program develops improved maize germplasm for the 6 to 7 million hectares of maize grown between the meridians of Cancer and Capricorn at altitudes over 1600 masl. Since 1984, nine white- and five yellow-grained populations were formed for use in developing OPV and as sources for inbred and hybrid development (Eagles and Lothrop, 1994). One heterotic pattern (Pop902 $\times$ Pop903) has been formed and improved by RRS. Two testers have been used to represent heterotic group A (CML242 and CML244), and two testers to represent heterotic group B (CML246 and CML349). CIMMYT has released 26 highland inbred lines (CIMMYT, 2004), 11 of which were included in this study. Among the 11 lines included in our study, five are derived from Pop85 (designated as heterotic group A), two from Pop800 (heterotic group B), one from Pop86, and three are recycled. In a PCoA of these highland CMLs, three sister lines derived from Pop85 (CML241, CML242, CML243) grouped closely together (Fig. 3). These lines, along with CML239, CML245, CML351, and CML353, are from heterotic group A and have semiflint grain texture. These were well separated from the three semident lines (CML246, CML349, and CML355) assigned to heterotic group B. 


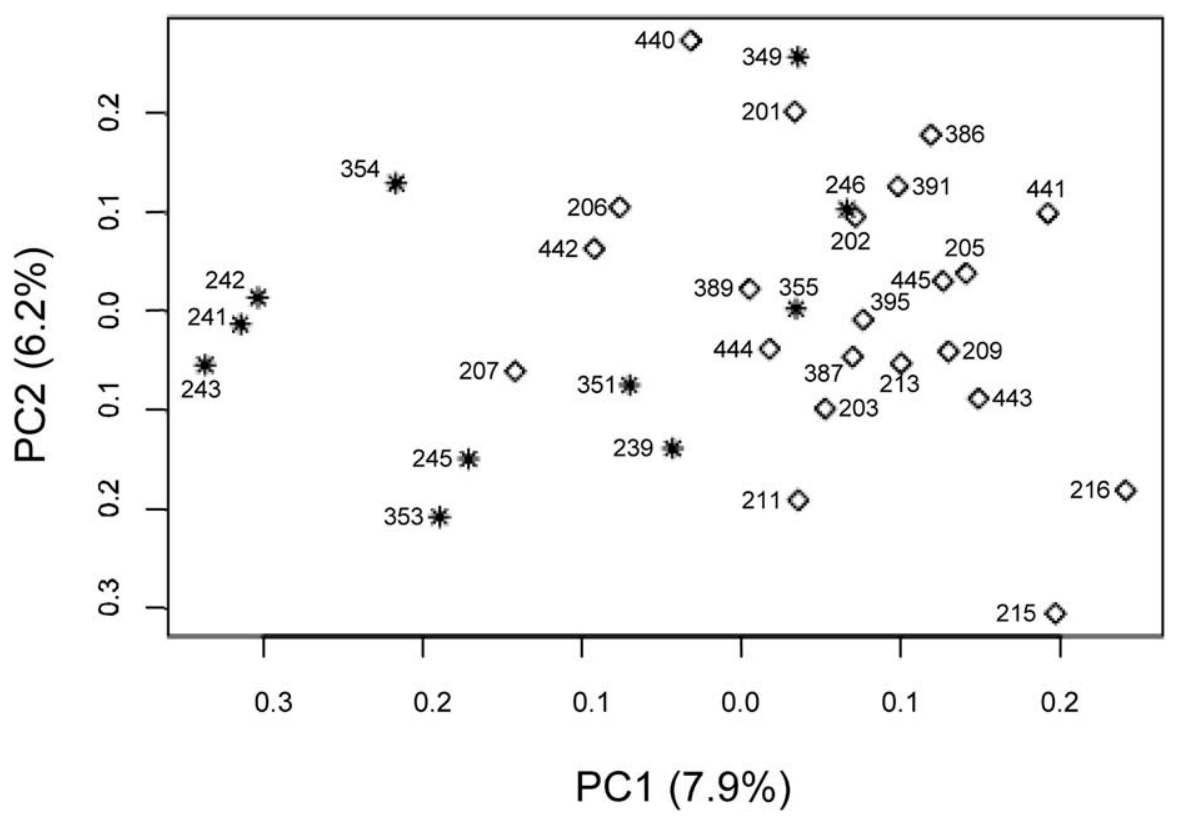

Fig. 3. Principal coordinate analysis based on modified Roger's distance. PC1 and PC2 are the first and second principal coordinate, respectively. Tropical highland $(*)$ and midaltitude $(\diamond)$ CIMMYT maize lines.

The separation of dent and flint (or semident and semiflint) occurs with CMLs from other megaenvironments although not as distinctly as we found with this highland group (Fig. 1). The flint vs. dent heterotic pattern has been used by CIMMYT and other hybrid maize breeding programs (Vasal et al., 1999; Reif et al., 2003a) and should continue to be exploited and even increased.

\section{Relationships among Subtropical, Midaltitude, Highland, Lowland Tropical, U.S., Canadian, and European germplasm}

The UPGMA cluster analysis of all inbred lines employed in this study is shown in Fig. 4. Five European flint lines (D171, DK105, KW2, F2, and F7) clustered closely together and were well separated from the European dents (D06, D32, and KW1), U.S. inbreds, and CMLs. An apparent genetic separation was found between the inbreds derived from an Iowa corn borer synthetic (B90, B91, B97, and B99) and the lines from Iowa stiff stalk synthetic (B73 and its derivatives R229 and R230). Among the CMLs, eight groups of closely related sister lines clustered together, a pattern seen in previous studies of CIMMYT inbred lines (Warburton et al., 2002; Xia et al., 2004).

It was much more difficult to find a clear clustering based on the megaenvironments for which lines were bred, including among the 10 tropical lowland CMLs included for comparison purposes. The CIMMYT subtropical, tropical lowland, midaltitude, and highland populations and pools, because of their similar and mixed origins, are not genetically distinct. For example, most of the tropical highland CMLs tested here derive from Pop85, which is composed of 55\% highland germplasm and $45 \%$ tropical lowland, subtropical, and U.S. Corn Belt maize materials. The midaltitude lines were selected from populations that have progenitors shared by the tropical lowland and subtropical CMLs. In addi- tion, the tropical lowland and subtropical CMLs also have U.S. Corn Belt, Southern and Central American, Caribbean, Asian, and Tuxpeño race germplasm in their backgrounds. Lack of clustering based on megaenvironment is consistent with previous studies in which approximately $90 \%$ of molecular variance was found within and $10 \%$ among the CIMMYT tropical and subtropical populations, illustrating a low genetic distance among CIMMYT populations and pools (Reif et al., 2003a, 2003b).

In an analysis using only tropical highland and midaltitude CMLs, more clearly defined separation is seen in a PCoA (Fig. 3). Many of the lines from tropical highland populations show a greater distance from lines derived from midaltitude populations, leading to speculation that hybrids between the two environments may show good heterosis. However, extensive testing of the hybrids in both environments would be necessary to determine the environmental adaptation retained by the hybrids.

\section{Recommendations for Hybrid Breeding with Nontemperate Maize}

In previous studies, molecular data have been useful to analyze the genetic similarity among the inbred lines developed from well-established heterotic groups with clear pedigree information, such as is found in most temperate breeding programs (Dubreuil et al., 1996; Pejic et al., 1998; Senior et al., 1998). However, markers were not as useful to group CIMMYT inbred lines according to their origins, and obvious heterotic groups are not apparent due to the unique breeding methodologies of the CIMMYT maize program, which initially emphasized developing germplasm with a wide germplasm base (for creation of OPV) and only relatively recently has begun to develop heterotic groups. These results are similar to those reported on a smaller subset 


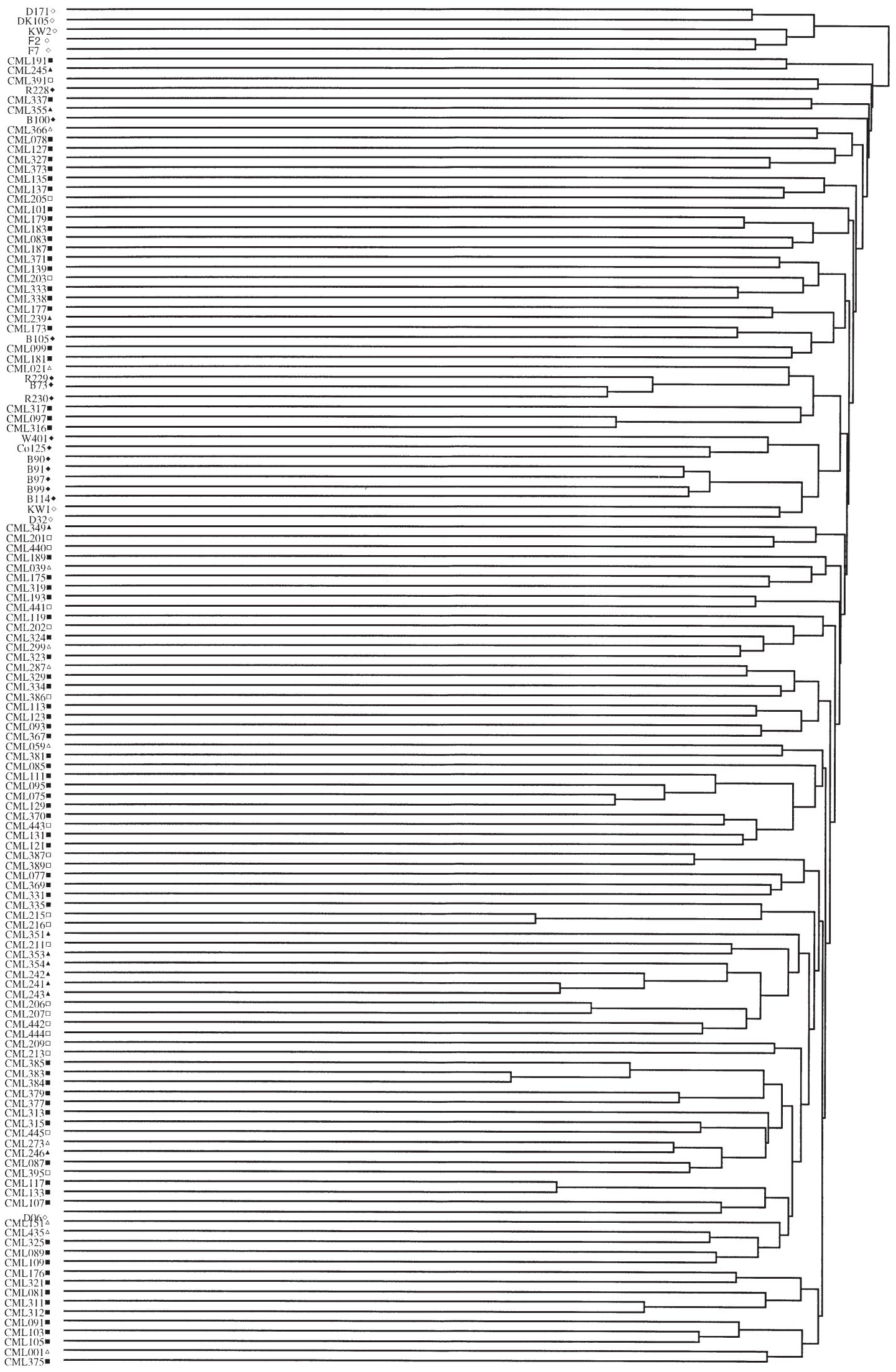

\begin{tabular}{rrrrrrrrr}
\hline & 1 & & & & & \\
0.0 & 0.1 & 0.2 & 0.3 & 0.4 & 0.5 & 0.6 & 0.7 & 0.8
\end{tabular}

Fig. 4. Associations among tropical $(\Delta)$, subtropical $(\square)$, midaltitude ( $\square$ ), highland $(\Delta)$, U.S./Canadian $(\diamond)$, and European $(\diamond)$ maize germplasm revealed by unweighted paired group method using arithmetic averages cluster analysis based on modified Roger's distance (horizontal axis). 
of tropical CMLs analyzed with RFLPs (Betran et al., 2003). However, specific recommendations can be made to the breeders and users of CIMMYT inbred lines for hybrid maize development.

1. It is important for breeders to focus on the improvement of heterotic partners in an RRS program to maximize the yield of hybrid combinations. Clearly defined heterotic groups displaying maximum diversity between groups and minimum diversity within groups are the most efficient method to achieve this (Hallauer et al., 1988). Because of the mixed composition of CIMMYT maize populations and pools, many generations of RRS may be necessary before the lines from each heterotic partner begin to be signficantly diverged. Molecular markers can speed the identification and divergence of heterotic groups in conjunction with crossing performance in an RRS program. This can be done by identifying the best lines in each heterotic group based on per se field performance. The number of inbred lines per group would then be reduced using marker data to choose those lines that are the most genetically distant from the lines in the opposite heterotic group, and the most similar to the mean of the lines from the same heterotic group. Marker analysis should be run every 1 to 2 generations to more quickly diverge the two groups from each other. Hybrid combinations between the two groups would then have a much higher probability of showing good combining ability than is currently seen.

2. The RRS programs must use an increased number of representative testers for each heterotic group, especially since many of the CIMMYT populations are very broad based. The number of testers may be reduced in the future as the heterotic groups become more uniform. These testers should be chosen based on their combining ability as well as their genetic distance from the inbred lines from opposite heterotic groups. In the subtropical maize breeding program, CML373 and CML384 (or CML321) are good testers representing Tuxpeño and non-Tuxpeño white maize germplasm, respectively. CML078 should not be used as a tester for any heterotic group due to its high genetic distance from all other subtropical inbreds (Fig. 1). In the development of midaltitude maize lines, new testers should be chosen for the four pairs of heterotic partner populations in RRS. CML202 and CML206 have already been replaced with new testers; the new testers will have to be fingerprinted to make sure they are representative of the heterotic groups they were selected to represent and diverged from the opposite group. In the tropical highland maize breeding program, CML242 and CML246 are good representative testers of flint and dent maize lines, respectively, and two more testers may be needed for the improvement of Pop902 and Pop903 in an RRS program.
3. The Tuxpeño race of maize is quite different from other tropical and subtropical maize races (Reif et al., 2003a, 2003b) and shows good heterosis in population crosses (Vasal et al., 1992b). New heterotic populations could be established along the patterns of Tuxpeño vs. non-Tuxpeño races (without mixing, as was done in the past) to maximize the yield in hybrid combinations between the two groups.

\section{ACKNOWLEDGMENTS}

The molecular marker analysis of this research was supported by funds from the German "Bundesministerium für wirtschaftliche Zusammenarbeit und Entwicklung" Projekt No. 98.7860.4-001-01. The authors wish to thank Salvador Ambriz, Leticia Diaz, and Scott Mclean for their excellent technical assistance, and to Drs. Marianne Banziger and Hugo Cordova for their critical reviews of the manuscript.

\section{REFERENCES}

Beck, D.L., F.J. Betran, M. Banziger, M. Willcox, and G.O. Edmeades. 1997. From landrace to hybrid: Strategies for the use of source populations and lines in the development of drought-tolerant cultivars. p. 369-382. In G.O. Edmeades et al. (ed.) Drought- and low N-tolerant maize. Proc. of a Symp., El Batan, Mexico. 25-29 Mar. 1996. CIMMYT, El Batan.

Beck, D.L., S.K. Vasal, and J. Crossa. 1991. Heterosis and combining ability among subtropical and temperate intermediate-maturity maize germplasm. Crop Sci. 31:68-73.

Betrán, F.J., J.M. Ribaut, D. Beck, and D. Gonzalez de Leon. 2003. Genetic diversity, specific combining ability, and heterosis in tropical maize under stress and nonstress environments. Crop Sci. 43: 797-806.

CIMMYT. 2004. Maize inbred lines released by CIMMYT. El Batan, Texcoco, Mexico.

Crossa, J., S.K. Vasal, and D.L. Beck. 1990. Combining ability estimates of CIMMYT tropical late yellow maize germplasm. Maydica 35:273-278.

Dubreuil, P., P. Dufour, E. Drejci, M. Causse, D. de Vienne, A. Gallais, and A. Charcosset. 1996. Organization of RFLP diversity among inbred lines of maize representing the most significant heterotic groups. Crop Sci. 36:790-799.

Duvick, D.N. 1984. Genetic diversity in major farm crops on the farm and in reserve. Econ. Bot. 38:157-174.

Eagles, H.A., and J.E. Lothrop. 1994. Highland maize from Central Mexico-Its origin, characteristics, and use in breeding programs. Crop Sci. 34:11-19.

Elder, J.K., and E.M. Southern. 1987. Computer-aided analysis of one dimensional restriction fragments gels. p. 165-172. In M.J. Bishop and C.J. Rawling (ed.) Nucleic acid and protein sequence analysis-A practical approach. IRL Press, Oxford, UK.

Enoki, H., H. Sato, and K. Koinuma. 2002. SSR anaylsis of genetic diversity among maize inbred lines adapted to cold regions of Japan. Theor. Appl. Genet. 104:1270-1277.

Evenson, R.E., and D. Gollin. 2003. Assessing the impact of the green revolution, 1960 to 2000. Science (Washington, DC) 300:758-762.

Frisch, M., M. Bohn, and A.E. Melchinger. 2000. Plabsim: Software for simulation of marker-assisted backcrossing. J. Hered. 91:86-87.

Gethi, J.C., J.A. Labate, K.R. Lamkey, M.E. Smith, and S. Kresovich. 2002. SSR variation in important U.S. maize inbred lines. Crop Sci. 42:951-957.

Goodman, M.M., and C.W. Stuber. 1983. Races of maize: VI. Isozyme variation among races of maize in Bolivia. Maydica 28:169-187.

Gower, J.C. 1966. Some distance properties of latent root and vector methods used in multivariate analysis. Biometrika 53:325-328.

Hallauer, A.R., W.A. Russell, and K.R. Lamkey. 1988. Corn breeding. p. 463-564. In G.F. Sprague and J.W. Dudley (ed.) Corn and corn improvement. 3rd ed. Agron. Monogr. 18. ASA, CSSA, and SSSA, Madison, WI. 
Ihaka, R., and R. Gentleman. 1996. A language for data analysis and graphics. J. Comput. Graph. Stat. 5:299-314.

Labate, J.A., K.R. Lamkey, M. Lee, and W.L. Woodman. 1999. Population genetics of increased hybrid performance between two maize populations under reciprocal recurrent selection. p. 127-137. In J.G. Coors and S. Pandey (ed.) The genetics and exploitation of heterosis in crops. ASA, CSSA, and SSSA, Madison, WI.

Lu, H., and R. Bernardo. 2001. Molecular marker diversity among current and historical maize inbreds. Theor. Appl. Genet. 103:613617.

Melchinger, A.E., M.M. Messmer, M. Lee, W.L. Woodman, and K.R. Lamkey. 1991. Diversity and relationships among U.S. maize inbreds revealed by restriction length polymorphisms. Crop Sci. 31: 669-678.

Messmer, M.M., A.E. Melchinger, J. Boppenmaier, R. Herrmann, and E. Brunklaus-Jung. 1992. RFLP analyses of early-maturing European maize germplasm: I. Genetic diversity among flint and dent inbreds. Theor. Appl. Genet. 83:1003-1012.

Morris, M.L. 2001. Assessing the benefits of international maize breeding research: An overview of the global maize impacts study. p. 25-34. In P.L. Pingali (ed.) CIMMYT 1999-2000 world maize facts and trends. Meeting world maize needs: Technological opportunities and priorities for the public sector. CIMMYT, D.F. Mexico.

Pejic, I., P. Ajmone-Marsan, M. Morgante, V. Kovumplick, P. Castiglioni, G. Taramino, and M. Motto. 1998. Comparative analysis of genetic similarity among maize inbred lines detected by RFLPs, RAPDs, SSRs, and AFLPs. Theor. Appl. Genet. 97:1248-1255.

Rebourg, C., M. Chastanet, B. Gouesnard, C. Welcker, P. Dubreuil, and A. Charcosset. 2003. Maize introduction into Europe: The history reviewed in the light of molecular data. Theor. Appl. Genet. 106:895-903

Reif, J.C., A.E. Melchinger, X.C. Xia, M.L. Warburton, D.A. Hoisington, S.K. Vasal, D. Beck, M. Bohn, and M. Frisch. 2003a. Use of SSRs for establishing heterotic groups in subtropical maize. Theor. Appl. Genet. 107:947-957.

Reif, J.C., A.E. Melchinger, X.C. Xia, M.L. Warburton, D.A. Hoisington, S.K. Vasal, G. Srinivasan, M. Bohn, and M. Frisch. 2003b. Genetic distance based on the simple sequence repeats and heterosis in the tropical maize populations. Crop Sci. 43:1275-1282.

Senior, M.L., J.P. Murphy, M.M. Goodman, and C.W. Stuber. 1998.
Utility of SSRs for determining genetic similarities and relationships in maize using an agarose gel system. Crop Sci. 38:1088-1098.

Smith, J.S.C. 1988. The diversity of U.S. hybrid maize germplasm: Isozymic and chromatographic evidence. Crop Sci. 28:63-70.

Smith, J.S.C., and O.S. Smith. 1989. Comparison of heterosis among hybrids as a measure of hybrid relatedness with that to be expected on the basis of pedigree. Maize Genet. Coop. Newsl. 63:86-87.

Smith, J.S.C., E.C.L. Chin, H. Shu, O.S. Smith, S.J. Wall, M.L. Senior, S.E. Mitchell, S. Kresovich, and J. Ziegle. 1997. An evaluation of the utility of SSR loci as molecular markers in maize (Zea mays L.): Comparisons with data from RFLPs and pedigree. Theor. Appl. Genet. 95:163-173.

Troyer, A.F., S.J. Openshaw, and K.H. Knittle. 1988. Measurement of genetic diversity among popular commercial corn hybrids. Crop Sci. 28:481-485.

Vasal, S.K., H.S. Cordova, S. Pandey, and G. Srinivasan. 1999. Tropical maize and heterosis. p. 363-373. In J.G. Coors and S. Pandey (ed.) The genetics and exploitation of heterosis in crops. CSSA, Madison, WI.

Vasal, S.K., G. Srinivasan, D.L. Beck, J. Crossa, S. Pandey, and C. De Leon. 1992a. Heterosis and combining ability of CIMMYT's tropical late white maize germplasm. Maydica 37:217-223.

Vasal, S.K., G. Srinivasan, J. Crossa, and D.L. Beck. 1992b. Heterosis and combining ability of CIMMYT's subtropical and temperate early-maturity maize germplasm. Crop Sci. 32:884-890.

Warburton, M.L., X.C. Xia, J. Crossa, J. Franco, A.E. Melchinger, M. Frisch, M. Bohn, and D.A. Hoisington. 2002. Genetic characterization of CIMMYT maize inbred lines and open pollinated populations using large scale fingerprinting methods. Crop Sci. 42:1832-1840.

Wellhausen, E.J. 1978. Recent developments in maize breeding in the tropics. p. 59-91. In D.B. Walden (ed.) Maize breeding and genetics. John Wiley \& Sons, New York.

Wright, S. 1978. Evolution and genetics of populations. Vol. IV. The Univ. of Chicago Press, Chicago.

Xia, X.C., J.C. Reif, D.A. Hoisington, A.E. Melchinger, M. Frisch, and M.L. Warburton. 2004. Genetic diversity among CIMMYT maize inbred lines investigated with SSR markers: I. Lowland tropical maize. Crop Sci. 44:2230-2237.

Yuan, L.X., J.H. Fu, S.H. Zhang, X. Liu, Z. Peng, X.H. Li, M.L. Warburton, and M. Khairallah. 2001. Heterotic grouping of maize inbred lines using RFLP and SSR markers. Acta Agron. Sinica 27:149-156. 